\title{
BMJ Open Quality Improving blood pressure screening and control at an academic health system
}

\author{
Ulfat Shaikh, Julie Petray, David H Wisner
}

To cite: Shaikh U, Petray J, Wisner DH. Improving blood pressure screening and control at an academic health system. BMJ Open Quality 2020;9:e000614. doi:10.1136/ bmjoq-2018-000614

Received 22 December 2018 Revised 11 February 2020 Accepted 24 February 2020
Check for updates

(c) Author(s) (or their employer(s)) 2020. Re-use permitted under CC BY-NC. No commercial re-use. See rights and permissions. Published by BMJ.

University of California Davis Health, Sacramento, California, USA

Correspondence to

Dr Ulfat Shaikh;

ushaikh@ucdavis.edu

\section{ABSTRACT}

The goal of the University of California Davis Health Blood Pressure (BP) Quality Improvement Initiative was to improve the diagnosis, management and control of high BP. Patients aged 18-85 years were included in the initiative. Lean A3 problem solving was used to implement the following evidence-based interventions based on stakeholder interviews, value stream mapping and the Centers for Disease Control and Prevention's Million Hearts Initiative: staff training on accurate BP measurement, visual cues and reminders for BP screening, virtual case-based videoconferences, standardised clinical management algorithm, academic detailing visits, clinical decision support tools, access to pharmacists for medication comanagement, clinician workflow modification, patient education and access to home BP monitors. Following implementation of interventions, accurate screening of BP increased from $14 \%$ to $87 \%$ and BP control increased from $62 \%$ to $75 \%$. Strategies that contributed the most to improvements were using a teambased approach, adjusting clinic workflow and frequent communication of results to staff.

\section{INTRODUCTION}

Approximately 100 million, or $45 \%$ of all adults in the USA, have high blood pressure (BP). ${ }^{1}$ Hypertension is the most common cause of cardiovascular disease-related deaths, with 79000 deaths annually attributable to high BP. During 2005-2015, the number of deaths due to high BP rose by $38 \%$. It is estimated that by 2035 , the total direct costs of high BP will be approximately $\$ 220$ billion. ${ }^{1}$ Reducing the average population systolic BP by $10 \mathrm{~mm}$ $\mathrm{Hg}$ can reduce the risk of major cardiovascular disease events by $20 \%$, coronary heart disease by $17 \%$, stroke by $27 \%$, heart failure by $28 \%$, cardiovascular disease deaths by $25 \%$ and deaths from all causes by $13 \% .{ }^{2}$ Every $10 \%$ increase in hypertension treatment prevents an additional 14000 deaths. ${ }^{3}$

Health system approaches for BP screening and control include one or a combination of quality improvement (QI) interventions, including healthcare provider education, nursing education, patient education, provider reminders, provider audit and feedback, changes in the composition and roles of healthcare teams, patient reminders and access to BP monitors for home measurements. $^{4-6}$ Published literature on large-scale system-level approaches predominately describes experiences at private and government-owned integrated healthcare organisations. Success and challenges with implementation of such interventions at large public safety-net academic health centres have not been sufficiently described.

The goal of the University of California Davis (UC Davis) Health Blood Pressure QI Initiative was to improve the accurate diagnosis, management and control of high BP. The objectives were to increase the proportion of patients $>18$ years of age at UC Davis Health who are accurately screened for hypertension and increase the proportion of patients with BP less than 140/90 $\mathrm{mm} \mathrm{Hg}$. Our hypothesis was that a multifaceted QI intervention will improve BP screening and control at UC Davis Health.

\section{METHODS}

UC Davis Health is an academic health centre located in Sacramento in Northern California and includes the UC Davis Medical Center, UC Davis School of Medicine, The Betty Irene Moore School of Nursing at UC Davis, UC Davis Academic Clinics, Network \& Affiliates Division, UC Davis Medical Group and the UC Davis Health Comprehensive Cancer Center. The UC Davis Medical Group employs approximately 1500 physicians and staff who provide outpatient care at 380000 primary care visits annually. Participants in this QI initiative were physicians, nurses, medical assistants, pharmacists and clinic staff who deliver primary care to adult patients at UC Davis Medical Group's 17 outpatient primary care clinics. Patients aged $18-85$ years with a diagnosis of hypertension who had at least one outpatient primary care encounter at UC Davis Health during the measurement year were included in the initiative.

Following a literature review of successful population and health-system level interventions, interviews were conducted with key stakeholders at UC Davis Health, including physician, nurses, pharmacists, health 
educators and patients, to identify value and assess challenges and opportunities for improvement of BP screening and control. The interviews elicited information on successful strategies currently employed at UC Davis Health that could be enhanced or spread, local challenges to BP management and ideas for potential interventions. Current and ideal clinical processes for BP screening and control at UC Davis Health clinics were studied through value stream mapping, and cause-and-effect and key driver diagrams were developed in collaboration with experts and key stakeholders.

The UC Davis Health BP Screening and Control Quality Improvement initiative was implemented in 2016-2018 and used Lean A3 problem solving to design and iteratively implement interventions. Lean A3 problem solving is a standardised QI framework that enables frontline workers to develop, test and implement changes and allows learning through trial and error, consensus building and communication. ${ }^{7}$ Key principles are integrating frontline workers into the improvement process, specifying value in the eyes of the customers (in this case, our patients and clinicians), value stream mapping, establishing flow, rapid iterative testing and adaptation and continuous improvement.

We used iterative testing to implement the following evidence-based interventions, based on information obtained from our literature review, stakeholder interviews, process mapping, key driver diagrams and the Centers for Disease Control and Prevention's Million Hearts Initiative: (1) clinician-focused interventions: nurse and medical assistant training on BP measurement, visual cues and reminders for BP screening at the pointof-care, virtual case-based videoconferences, distribution of pocket cards with standardised clinical management algorithm; (2) system-focused interventions: academic detailing visits, clinical decision support tools, access to pharmacists for medication comanagement, clinician workflow modifications, nursing follow-up visits; (3) patient-focused interventions: BP education videos and classes for patients, access to home BP monitors. ${ }^{8}$

The following outcomes were assessed through retrospective data analysis from electronic health records (EHR):

(1) percentage of patients whose BP was remeasured after at least 5 min of rest if their initial $\mathrm{BP}$ during the visit was $\geq 140 / 90 \mathrm{~mm} \mathrm{Hg}$ (process measure); (2) percentage of patients whose most recent BP was $<140 / 90 \mathrm{~mm} \mathrm{Hg}$ (outcome measure). Monthly data were analysed using run charts, which enabled us to visually display and assess outcomes in a time sequence. The initiative was approved by the UC Davis Institutional Review Board.

\section{RESULTS}

The following evidence-based interventions at UC Davis Health based on information obtained from our literature review, key stakeholder interviews, patient focus groups, process mapping, a key driver diagram and the Centers for Disease Control and Prevention's Million Hearts Initiative (figure 1$)^{8}$ :

\section{Standardised clinical algorithm}

Physicians and trainees were sent a printed pocket card with a standardised clinical management algorithm for
Goal

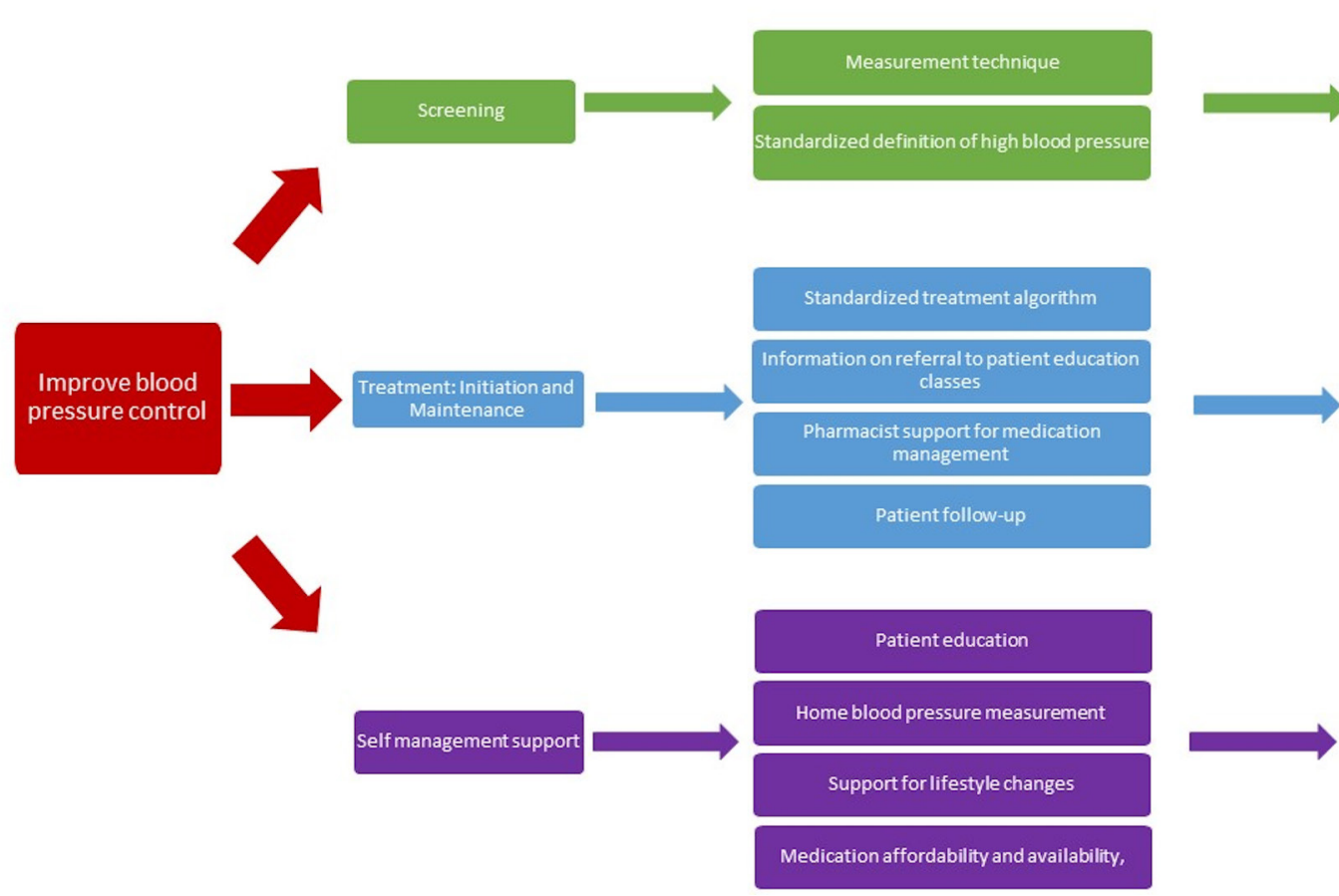


hypertension, published by the Capitol Region Right Care Initiative. The pocket card was initially based on the Eighth Joint National Committee on Prevention, Detection, Evaluation, and Treatment (JNC-8) guidelines and was subsequently revised to incorporate the 2017 ACC/ AHA Guideline for the Prevention, Detection, Evaluation, and Management of High Blood Pressure in Adults. ${ }^{9}$

\section{Medical director incentive}

Accurate BP screening was selected as one of three quality goals during 2016-2017 for clinic medical directors at UC Davis Health. Medical directors were eligible to earn year-end incentive payments for achievement of these goals, the amounts of which were based on the size and complexity of their clinic site.

\section{Standardised measurement of blood pressure}

In-person training that included demonstration videos on accurately measuring $\mathrm{BP}$ was provided to nurses and medical assistants and was added to the list of competencies for newly hired staff. Key learning points were: using the correct cuff size, placing the cuff on a bare arm, applying the cuff snugly allowing space for no more than two fingers under the cuff, not talking to the patient while measuring BP, keeping the upper arm at heart level, ensuring that the arm is supported, patients' feet are on the floor and their legs are uncrossed. If a patient's BP was $\geq 140 / 90$, nurses and medical assistants were instructed to retake the $\mathrm{BP}$ after at least a $5 \mathrm{~min}$ period of rest.

\section{Modifications to clinic workflow}

Workflow for nurses and medical assistants was adjusted to allow patients to rest for at least $5 \mathrm{~min}$ if their initial $\mathrm{BP}$ was high, before their BP was repeated. All staff were further instructed to record both BPs in the visit flowsheet instead of in another part of the visit note. Noncopayment visits with a clinic nurse in 2 weeks to recheck $\mathrm{BP}$ were recommended.

\section{Visual cues and reminders}

Fliers with a figure showing accurate $\mathrm{BP}$ measurement techniques were attached to BP machines. Posters with this information were displayed in areas of the clinic where vital signs were measured. Clinic-level results of the BP initiative were regularly communicated with leadership and staff through monthly emails, at staff meetings and on a QI dashboard displayed in clinics.

\section{Case-based videoconferences}

Through four 1-hour interactive case-based webinars that provided continuing education credits, experts in BP management reviewed the following key topics: management of hypertension in complex patients, barriers to antihypertensive medication compliance and $\mathrm{BP}$ goal attainment, resistant hypertension and advances in hypertension management. These topics were identified through a survey of UC Davis Health primary care providers. Webinars were scheduled once a month at lunchtime. A challenge was low attendance of physicians due to clinical care running over into the noon hour.

\section{Patient self-management support}

A 20 min video on hypertension was made available that could be shared with patients through an EHR order. Based on their preference, patients could receive a link to the video either through email or through their EHR patient portal. In addition, information on the following patient education resources available at UC Davis Health were disseminated to clinicians and staff: patient workshops on heart health, healthy weight, nutrition, physical activity, stress management and smoking cessation. We also provided information on a comprehensive 12 week BP control programme for complex patients which is currently being scaled up. During the pilot phases of this programme, approximately 200 patients received wireless BP monitors annually which conveyed home BP measurements to their primary care providers through the EHR.

\section{Academic detailing visits}

Peer-to-peer educational outreach through academic detailing visits helped our team convey three key messages to our clinicians and staff in a brief $3-5$ min format: Repeat BP if first BP $>140 / 90 \mathrm{~mm} \mathrm{Hg}$, recommendation that medical assistants and nurses place a pending order in the EHR for referral to the video on hypertension and/or patient education and self-management classes at UC Davis Health that the physicians could sign if indicated and information on how to refer patients for telemedicine resources such as ambulatory case management telephonic support from pharmacists, nurses and social workers and the newly established nephrology e-consultation programme for hypertension. Although these resources existed prior to the BP Initiative, information on their availability was not widely known. ${ }^{10}$

Following implementation of interventions in June 2016, accurate screening of BP increased from $14 \%$ to $87 \%$ (figure 2). Before the initiative, an average of $62 \%$ of our patients had BP $<140 / 90$. Currently, $75 \%$ of our patients are at this BP goal, which is an $18 \%$ improvement over baseline. Approximately $30 \%$ of patients with initial $\mathrm{BP} \geq 140 / 90$, had BP $<140 / 90$ after it was remeasured at the same visit following a rest period (figure 2). Aspects of our intervention that contributed most significantly to improvements were using a team-based approach, adjusting clinic workflow and frequent communication of results to staff. Results of our interventions are graphically depicted using a run chart in figure 3 .

\section{DISCUSSION}

The UC Davis Health BP Initiative demonstrated that standardising BP measurement, using a team-based approach, modifying clinic workflow and prioritising $\mathrm{BP}$ control as part of system-wide QI goals can improve BP screening and control, even in large healthcare systems serving complex and high-risk populations. The percentage of patients in whom $\mathrm{BP}$ was remeasured 


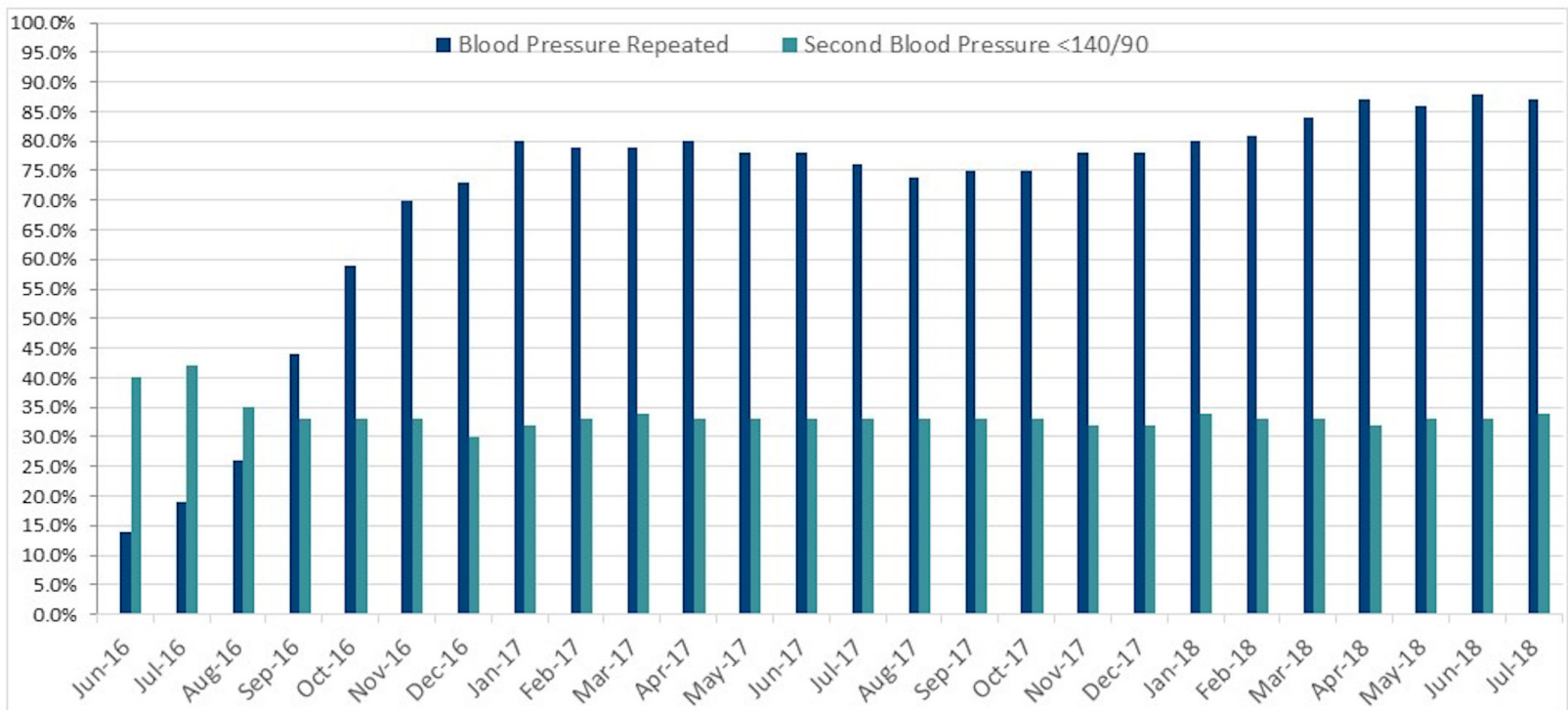

Figure 2 Results of intervention to repeat blood pressure if initial measurement was $>140 / 90 \mathrm{~mm}$ Hg. Percentage of patients for whom blood pressure was repeated after at least 5 min of rest if initial blood pressure $\geq 140 / 90 \mathrm{~mm} \mathrm{Hg}$ )

if their initial BP was high increased from $14 \%$ to $87 \%$ and the percentage of patients whose BP was controlled increased from $62 \%$ to $75 \%$.

Approximately $30 \%$ of patients with initial $\mathrm{BP} \geq 140 / 90 \mathrm{~mm}$ $\mathrm{Hg}$ had $\mathrm{BP}<140 / 90 \mathrm{~mm} \mathrm{Hg}$ after it was remeasured at the same visit following at least a $5 \mathrm{~min}$ rest period. Our results align with published research that estimates the prevalence of white coat hypertension and white coat effect in medical offices at $15 \%-30 \%$. White coat effect, first described in 1983 and distinct from white coat hypertension, is transient elevation in BP in the medical office caused by an alerting response to a physician or nurse through reflex activation of the sympathetic nervous system. ${ }^{11}$ Accurately identifying patients who have white-coat effect can prevent overdiagnosis and overtreatment of hypertension, misclassification of stage of hypertension and help focus efforts on patients who would benefit the most from lifestyle changes and pharmacological interventions. ${ }^{12}$ Since inaccurate measurement of BP results in so many repercussions to patients and the health system, substantial effort and resources during the period of this QI intervention were directed towards ensuring accurate measurement and recording of BP.

A limitation of our QI initiative was that it was implemented at a single academic health system. However, the 17 outpatient primary care clinics that are part of UC Davis Health are diverse in terms of geographic location, insurance status of patients, population served and the presence of health professions trainees. An issue faced by the QI team was the evolution of clinical guidelines for hypertension. While the UC Davis Health BP Initiative used recommendations from the Million Hearts Initiative and the HEDIS: Controlling Blood Pressure Measure, in November 2017 the American College of Cardiology and the American Heart Association released a new clinical practice guideline which lowered the threshold for hypertension to $130 / 80 \mathrm{~mm} \mathrm{Hg} .{ }^{13}$ Based on feedback from key

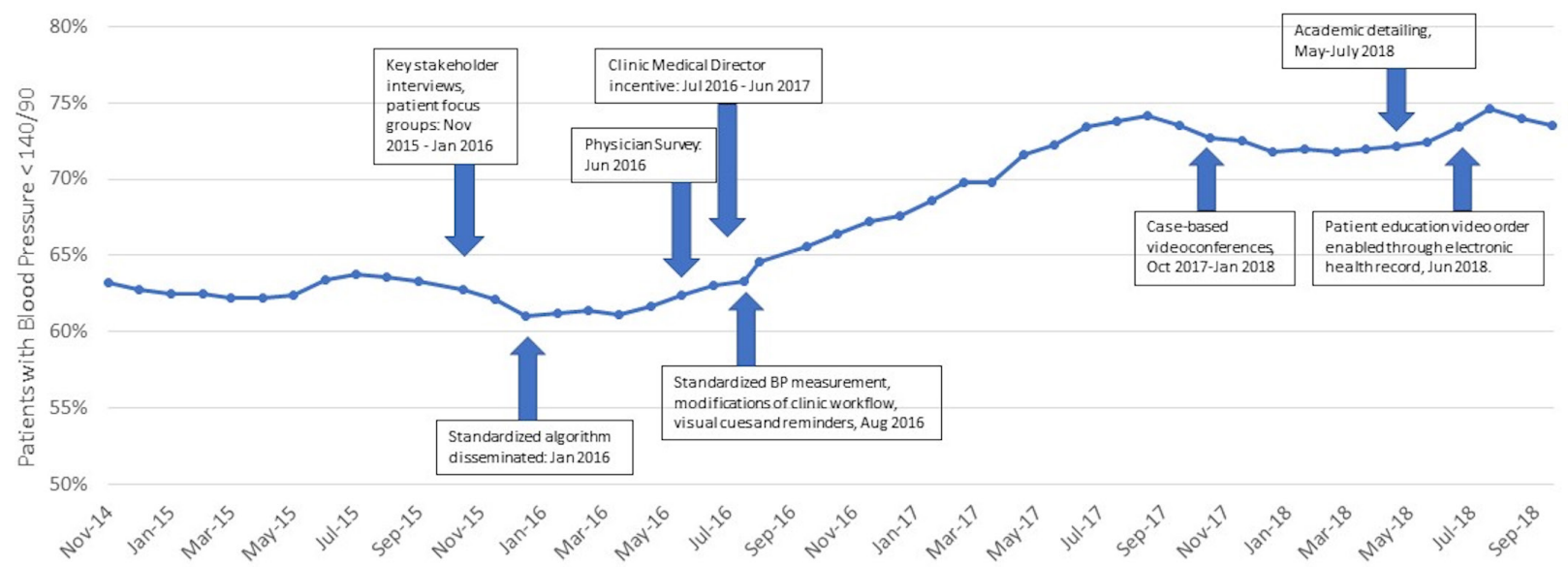

Figure 3 Run chart: UC Davis Health Blood Pressure Control Initiative. Percentage of patients (18-75 years) at UC Davis Health Primary Care Clinics with most recent blood pressure $<140 / 90 \mathrm{~mm} \mathrm{Hg}$. BP, blood pressure. 
stakeholders at UC Davis Health, we made the decision to continue using the threshold of $140 / 90 \mathrm{~mm} \mathrm{Hg}$ for the purposes of our QI initiative.

Despite the evidence around white coat effect, several clinics in our QI initiative reported that the period of rest between two consecutive BP measurements remained a continuing challenge, since some physicians perceived that it disrupted and caused delays in their workflow. Although this perception was mitigated through peerto-peer educational outreach in the form of academic detailing visits, sustainability of clinical workflow redesign can be challenging until changes are hardwired into the system. ${ }^{10}{ }^{14}$ Our next steps are to assess the feasibly of integrating clinical decision support tools into our EHR to help sustain interventions. Promising tools to improve screening and management of hypertension include alerts, clinical reminders, standardised documentation templates and order sets. ${ }^{15} 16$

During the period of the BP initiative, UC Davis Health was engaged in a statewide pay-for-performance programme which, in addition to BP control, targeted several other high priority areas including opioid use, access to care and optimal use of radiographic imaging. We believe that other health systems face similar challenges with multiple QI priorities in the setting of finite resources. We were successful in handling some of these challenges through developing and using a centralised infrastructure for data collection, data analysis and tracking of outcomes for these various $\mathrm{QI}$ focus areas. Further research that assesses how health systems successfully build capacity for and balance multiple QI priorities will be timely and helpful as we navigate health reform and value-based care.

In conclusion, the UC Davis Health BP Initiative demonstrated that QI interventions to standardise BP measurement, use a team-based approach and modify clinic workflow improved BP screening and control. Key considerations for future QI initiatives are the evolution of clinical guidelines and BP control thresholds, ensuring that clinical workflow changes are hardwired and building centralised QI capacity within health systems to simultaneously balance and support multiple QI priorities.

Acknowledgements The authors would like to acknowledge Kurt Slapnik and Gregory Maynard for supporting the UC Davis Health Blood Pressure Control Initiative. They would like to thank Timothy Cutler, Dayna Isaacs, Niti Madan, Stephanie Roberts, Huong Sandhu and Glee Van Loon for serving as instructors at case-based videoconferences and academic detailing visits. This work would not have been successful without the dedication and support of primary care clinicians and staff at UC Davis Health.

Contributors All authors participated in the work and have reviewed and approved this manuscript before submission. US contributed to the project concept and design, implementation of interventions, acquisition of data, analysis of data, drafting of the manuscript and study supervision. JP and DHW contributed to the project design, implementation of interventions, drafting of the manuscript and critical revision of the manuscript.

Funding This study was funded by Practice Management Board, University of California Davis Health.
Competing interests None declared.

Patient and public involvement Patients and/or the public were involved in the design, or conduct, or reporting, or dissemination plans of this research. Refer to the Methods section for further details.

Patient consent for publication Not required.

Ethics approval Institutional review and approved by UC Davis Institutional Review Board.

Provenance and peer review Not commissioned; externally peer reviewed. Data availability statement Data are available upon request.

Open access This is an open access article distributed in accordance with the Creative Commons Attribution Non Commercial (CC BY-NC 4.0) license, which permits others to distribute, remix, adapt, build upon this work non-commercially, and license their derivative works on different terms, provided the original work is properly cited, appropriate credit is given, any changes made indicated, and the use is non-commercial. See: http://creativecommons.org/licenses/by-nc/4.0/.

\section{REFERENCES}

1 Benjamin EJ, Virani SS, Callaway CW, et al. Heart disease and stroke Statistics-2018 update: a report from the American heart association. Circulation 2018:137:e67-492.

2 Ettehad D, Emdin CA, Kiran A, et al. Blood pressure lowering for prevention of cardiovascular disease and death: a systematic review and meta-analysis. Lancet 2016;387:957-67.

3 Farley TA, Dalal MA, Mostashari F, et al. Deaths preventable in the U.S. by improvements in use of clinical preventive services. Am J Prev Med 2010;38:600-9.

4 Fletcher RD, Amdur RL, Kolodner R, et al. Blood pressure control among US veterans: a large multiyear analysis of blood pressure data from the Veterans administration health data Repository. Circulation 2012;125:2462-8.

5 Jaffe MG, Lee GA, Young JD, et al. Improved blood pressure control associated with a large-scale hypertension program. JAMA 2013:310:699-705

6 Shaw KM, Handler J, Wall HK, et al. Improving blood pressure control in a large multiethnic California population through changes in health care delivery, 2004-2012. Prev Chronic Dis 2014:11:E191.

7 Shook J. Toyota's Secret: The A3 Report. MIT Sloan Manage Review 2009;50:30-3.

8 Centers for Disease Control and Prevention. Million hearts. Available: https://millionhearts.hhs.gov/ [Accessed 10 Oct 2018].

9 Capitol Region Right Care Initiative. Hypertension treatment algorithm, 2018. Available: https://rightcare.berkeley.edu/tools-andlinks [Accessed 30 Oct 2018].

10 Agency for Healthcare Research and Quality. Module 10. academic detailing as a quality improvement tool, 2013. Available: http://www. ahrq.gov/professionals/prevention-chronic-care/improve/system/ pfhandbook/mod10.html [Accessed May 2013].

11 Mancia G, Bertinieri G, Grassi G, et al. Effects of blood-pressure measurement by the doctor on patient's blood pressure and heart rate. Lancet 1983;2:695-8.

12 Franklin SS, Thijs L, Hansen TW, et al. White-coat hypertension: new insights from recent studies. Hypertension 2013;62:982-7.

13 Whelton PK, Carey RM, Aronow WS, et al. 2017 ACC/AHA/AAPA/ ABC/ACPM/AGS/APhA/ASH/ASPC/NMA/PCNA guideline for the prevention, detection, evaluation, and management of high blood pressure in adults: a report of the American College of Cardiology/ American heart association Task force on clinical practice guidelines. Hypertension 2018;71:e13-115.

14 Scoville R, Little K, Rakover J. Sustaining improvement. IHI white paper. Cambridge, Massachusetts: Institute for Healthcare Improvement, 2016.

15 Shelley D, Tseng T-Y, Matthews AG, et al. Technology-driven intervention to improve hypertension outcomes in community health centers. Am J Manag Care 2011;17:SP103-10.

16 Lopez PM, Divney A, Goldfeld K, et al. Feasibility and outcomes of an electronic health record intervention to improve hypertension management in Immigrant-serving primary care practices. Med Care 2019;57(Suppl 6 Suppl 2):S164-71. 